\title{
Role of School Administrators in Bullying Prevention in State Universities Laboratory Schools: Implication to Pre-service Training
}

\author{
Maria Lourdes G. Tan, EdD \\ marialourdestan71@gmail.com \\ Leyte Normal University, Paterno St., Tacloban City 6500, Leyte, Philippines
}

\begin{abstract}
School administrators' face significant challenge in addressing bullying in schools. This study utilized multiple case studies to investigate the forms, challenges, resolving mechanism, and intervention plan on anti-bullying of three (3) school administrators of different laboratory schools in Leyte Philippines, purposely selected as respondents. It employed Colaizzi's descriptive phenomenological method of data analysis anchored on social cognitive theory utilizing in-depth semi-structured interviews, questionnaires, and voice recordings to gather data. Through triangulation, findings revealed that common forms of bullying were verbal and non-verbal: student to student, student to pre-service teacher, parent to pre-service teacher.

The administrators ' challenges were handling bullies, bullied children, pre-service teachers, and parents. Conducting regular parents-teachers meetings, effective classroom management, clear policy on anti-bullying, orientation both to students, parents, pre-service teachers were the measures initiated by the school. Results of the study point out to school administrators to review policies and provide vital counseling programs on anti-bullying. Future directions also emphasize the development and implementation of anti-bullying education to promote positive interaction among students, preservice teachers and parents.
\end{abstract}

Keywords : anti-bullying, school administrators, pre-service training, multi-case study

\section{Introduction}

Bullying, a trending concern by many schools, is described as aggressive behavior that gives discomfort and adverse effects on the child's well-being (Smith \& Ananiadou, 2013). It is not just a concern of students and teachers but also pre-service teachers, school administrators, and parents. Smith \& Ananiadou (2013). It is an unwanted behavior towards another with the intent to harm, putting the bullied victim in a situation hard for him to defend.

(Tolentino, 2016). It has been one of the major concerns in the Philippines and many schools around the world for the past years and is still a problem recently (Ananiadou et al., 2013). In the international setting, especially in the field of education, bullying is a significant concern among educators globally because it does affect not only the students but also the teacher and the whole school. It usually happens but is not focused and given prior attention. In America and the United Kingdom schools, numerous studies and researchers are ongoing to effectively respond to this problem (Maria, 2005). However, like in Greece, some schools tend to ignore it to protect their reputation and students (Asimopoulos et al., 2013). Locally, the Philippines adhere to the Republic Act of 10627 or Anti-Bullying Republic Act of 2013, which explains the act of bullying and 
directs school authorities to adopt policies concerning bullying inside the school premises. As documented by DepEd, despite this provision, there are still more than 1,700 cases of bullying, and only 60 percent were resolved (Flores, 2014). Therefore, bullying continues to be a problematic situation in the entire Philippines that needs attention and intervention (Edaño et al., 2016). These different reported cases of bullying challenge the capability of school administrators. It is on this premise that this research is conducted to carefully study how the school administrators deal with the bully, bullied party, and their parents.

School administrators guide teachers, students, and parents on its policy, specifically on bullying. Such a system helps the school mediate issues in bullying situations. However, in reality, it cannot be avoided that conflicts arise that challenge school heads on its ability to face the concerned parties and come up with a decision, action, and clear policy. The ultimate aim of this study is to explore how school administrators handle issues on bullying occurring in the school. The challenge lies in how they perform their role to face those challenges in terms of coming up with a decision and action appropriate to the child's developmental level without compromising the school's policy on anti-bullying. This study provides information and awareness of the forms of bullying in every school. It also includes data on how the school administrators respond and handle the bullying situation. This study will guide the school heads in coming up with a clear policy and viable anti-bullying programs beneficial for students, teachers, and parents without compromising the school policy.

\subsection{Research Questions}

Specifically, it seeks to answer the following questions:

1. What are the issues and problems met by the administrators on handling bullying?

2. How do the school administrators resolve students, pre-service teachers, parents, and teachers' concerns about bullying?

3. What the school administrators propose intervention plan to implement a viable anti-bullying program?

\subsection{Theoretical Framework}

This study relied on Burrhus Frederic Skinner's (1938) Operant Conditioning Theory that one way to understand behavior is to know first the cause. It means that once the object of bullying behavior is identified, it will not be hard to give the treatment. Furthermore, Operant Conditioning implies the change of action through reinforcement given after the desired behavior.

However, the Social Cognitive Theory of Bandura (1977) defined bullying as a social relationship that supports the conceptualization of the relationship between the individual and his social environment. The Social Cognitive Theory of Bandura (1977) states that children learn new behavior by watching and imitating people without considering if it is positive or negative. This theory helps understand the complexity of bullying behavior and its nature of involvement. It serves as a guide in developing the individualized intervention, and teachers bully perpetrators alternative, prosocial ways of interacting with others.

Moreover, the study also adopted Cooley's Symbolic Interaction Theory as adopted by Basibas (2010), which explained that individuals could create a solution to their problem. Applied to this study, it means that with the appropriate anti-bullying policies, training, and programs, both students, parents, teachers, and school administrators will be able to manage bullying concerns effectively. 


\section{Review of Literature}

\subsection{Forms of Bullying}

Bullying in the Philippines varies from student to student, student to teacher, and teacher to teacher scenarios. According to Paragus (2016), bullying usually happens in the classroom, focusing on verbal intimidation rather than physical bullying. Common factors of bullying among any students are feeling good in themselves, peer pressure, and home-life. Cadorna, Reyes, \& Tangalin (2015) added that students were being threatened in non-verbal such as hitting, physical attack, and taking the belongings.

There are three types of bullies well-known in schools today: physical, verbal, and relational bullies. Physical bullying like hitting, kicking, punching, and other physical exertion of energy towards another child. Verbal bullies use harsh words such as name-calling, insults, racial comments to degrade students' physical appearance. Finally, relational bullies singled out the bullied student from the peer group (Reyes, 2016).

\subsection{Issues, Problems Encountered by School Administrators in Handling Bullying}

School Administrators face numerous challenges and problems in addressing bullying cases in the school. As Bradshaw et al. (2007) mentioned, most students believe their school is not doing enough to prevent bullying, while most school staff feel their prevention efforts are adequate. As a result, many students do not report bullying to the school heads but rather to their parents or friends. Students are unwilling to talk and disclose the bullying incident because they are afraid the teachers will give less importance and not validate the situation and just dismiss the case (Mishna \& Alaggia, 2005). Their reluctance to report bullying to school staff likely stems from negative messages and lack of confidence in school heads' responses (Kowalski, Limber \& Itgatson, 2012).

Pointing out the training on anti-bullying, the majority of the school heads $(93 \%)$ indicated that their school had not implemented a bullying prevention policy. Only about half (54\%) had received training related to that policy. Although school administrators see the importance of bullying prevention, the multiple demands on their time, many roles, and tasks deprive them of focusing and making it their priority (Bradshaw et al., 2011). The evidence suggests that bullying increases when the teachers and school administrators lack the responsibility and commitment to respond to the students and other people concerned (Astor \& Benbenishty, 2007).

\subsection{School Administrators Guide on How to Handle Bullying}

The school's response in handling bullying cases plays an enormous role in regaining back the confidence of both students, teachers, and parents. Bradshaw et al. (2007) suggested how school administrators manage and help prevent bullying in their school as follows: (a) focus on the school climate by creating a positive environment where students feel safe and connected. (b) assess bullying to help raise awareness and motivate adults to take action. (c) raise and seek support for bullying prevention from school leaders, faculty, staff, and community partners. (d) coordinate and integrate prevention efforts for bullying and social and emotional problems. (e) respond consistently and appropriately on the spot whenever bullying is happening. (f) spend time talking with students and staff to express their views about bullying, on social and emotional issues, which will help address it and give appropriate action $(\mathrm{g})$ establish and enforce clear rules and policies on bullying. (h) increase adult supervision by identifying "hot spots" for immediate action behavior. (i) continue efforts over time. Finally, (j) provide training in bullying prevention and appropriate responses. 
School administrators could not do it alone. The solution is a coordinated effort of students, teachers, parents, and school administrators. Teachers play a significant role in preventing bullying as he has direct involvement and interaction with students (Yoon \& Barton, 2008). Teachers' knowledge and skills on addressing the case were found to be the premier determinants to decrease bullying circumstances (Kallestad \& Olweus, 2003). There are several ways to cope with and stop bullying: 1 . Students being bothered should; a) talk about it, b) avoid trouble, c) do not use force, and d) if annoyed online, do not reply (Carney, 2006). Children should report bullying situations (Adams, 2006). They should be encouraged to tell the bullying situation to their parents, older siblings, or a friend so that they will know what to do. The school authorities could give immediate and appropriate action to the problem and give the victim precautionary measures (Arnett, 2007). 2. The teacher should demonstrate proper behavior to make it a school-wide standard (Arnett, 2007). Classroom management should be close and increased supervision to promote kindness, cooperation, and communication. Let students be involved in policymaking and rules that may reduce bullying. Doing this will teach children the importance of respecting who they are (Casey-Cannon et al.,2001). 3. Parents also play an essential role in developing preventive strategies (Woods \& Wolke, 2003), such as modeling good behavior and promoting positive relationships between friends (Casey-Cannon et al., 2004).

However, it is not only the teacher who will undergo training on bullying. Hows (2005) mentioned that an effective way of handling bullying issues in school involves training and counseling both school administrators and parents. Pepler et al. (2008) pointed out that bullying behavior is sometimes also adapted at home. Therefore, the guidance of parents to the children is very much relevant. If the child's family shows how parental care and unpleasant discipline experiences of being bullied by siblings at home, the child is at risk of becoming the victim. In the recent meta-analysis examining anti-bullying programs worldwide, teacher and parent training are the most influential factor to decrease the case of bullying and victimization (Farrington \& Ttofi, 2011). The teacher and school administrators attend training and seminars on bullying intervention to provide knowledge and skills to handle the situation effectively (Asismopuolos et al., 2013). The recent study of Boulton et al. (2013) explained that aside from training, the Initial Teacher Education (ITE) should have programs to educate the students and teachers on both cyber and traditional bullying. These ideas are relevant, especially for our 21 st-century learners who encountered bullying through posting online, must know how to cope with it. Tennille (2004) explained that one way to decrease the issue of bullying in the school is the implementation of anti-bullying programs to orient the victims and bullies, Merrell (2001) coded that bullies are more intense and willing to fight because of their prosocial skills from families and peers as wells as lack of knowledge on the consequences of their action. Media report some cases that those who killed their classmates are the victims of bullying who retaliated in a destructive manner (Balcer \& Gerler, 2004).

Anti-bullying programs work by creating an environment where bullies will not be rewarded or tolerated (Adams, 2006). Schools will plan and implement changes to have successful bullying programs, which may include: policies and procedures, staff development, bullying assessments, curriculum support, and programming initiatives. Also, tapping consultants and experts in the field will help develop an anti-bullying program that best suits the school population Yoon et al. (2004). Schools can provide meaningful activities, interventions, and positive social interaction through role-playing, literature, and writing (Davies, 2003). Role-playing is used to describe the actions of bullies, victims, and bystanders (Dellasega, 2005). Watching movies and reading stories about bullying could be used to see what is going on in schools and what action should be performed (Roosevelt \& Logon, 2007). Art can also bridge the thoughts and feeling with reality on bullying (Stepney, 2001). Mandatory programs that provide role models for youth (Dellasega, 2005) and help students develop their strategies for conflict solutions (Mullin-Rindler, 2003).

Activities include not only the victim but also the bully. They need to see how hurtful their behavior is to realize their misdeed. Counseling bullies should be done individually rather than in groups to redirect their 
aggressive tendencies into power and leadership roles (Mullin-Rindler, 2003). These social skills training programs and character-education programs will help foster peer-relationship of a good friend and teach young people leadership skills (Young et al., 2006). In addition, these meaningful activities given to students can help overcome their preoccupation with being mean to others (Owens et al., 2000).

\section{Methodology}

\subsection{Research Design}

This study utilized a descriptive qualitative method, specifically, a multi-case study, to investigate the problems, resolve measures, and suggest anti-bullying programs. In addition, the study explores school administrators' experiences on how they handled bullying cases in their schools. The result of this inquiry would serve as the basis for crafting an effective school-based anti-bullying program.

\subsection{Research Setting}

This study was conducted in the selected state universities in Region VIII located in Biliran and Tacloban City, Leyte, Philippines. The researcher purposely confined the study in the said schools, a training institution catering from primary education to college. Schools programs and policies gathered in one direction to the University's vision and mission producing technologically and professionally competent human resources imbued with positive values needed for sustainable development.

\subsection{Research Participants}

The participants were the principals of the Laboratory School of the three (3) selected state universities in Region VIII. As participants in this study, school administrators tried their best to do their job despite their challenges in resolving bullying concerns. This study followed the protocol prescribed in conducting qualitative research:

1. The researcher submits the participant's name with pseudo names in the transcript.

2. The researcher gives them the freedom to continue as a participant in the study.

3. The researcher observed the confidentiality of the information and audio-recording throughout the study with the assurance that this data will be used in this research only.

\subsection{Sampling}

Three research participants of this study were chosen through purposive sampling. Based on the researcher's judgment when choosing the study participants (Patton, 2002). This research involves identifying and selecting a group of knowledgeable individuals who shared a common field of interest since they were both school principals of the Basic Education in the College of Education (Creswell \& Clark, 2011).

\subsection{Research Instrument}

This study utilized the researcher-made interview instrument, the interview questionnaire used in the indepth semi-structural interview to extract the responses of the school administrators regarding the forms, challenges, management style, and suggested an anti-bullying program. The interview guide was submitted for validation by experts. There are two parts. Part I aimed to gather information on the participant's data such 
as name, age, school name, educational attainment, and designation. Part II was about school administrators in bullying management. Experts validated this instrument before the researcher gave it to the participants.

\subsection{Data Collection Procedure}

The participants were requested to answer the questionnaire. Then, an in-depth semi-structured interview was conducted to further elaborate and validate their answers. The researcher conducted the following: (1) the researcher sought a permit from the school administrator to conduct research. (2) then, have a pilot test of the interview questionnaire and interview process. (3) Participant A sign the consent form and answered. (4) answer the interview questionnaire. (5) conduct of in-depth semi-structured interview (for interview reflection). (6) have a triangulation through documentation and direct observation of the participant. (7) then transcription, data coding of audio-recorded interviews, and interpretation per case. (8) going back to the participant to confirm the transcribed data. (9) conduct of steps 3-7 to Participant B. (10) literal Replication through similarities. (11) Add new questions in the interview protocol (if needed). (12) conduct of steps 3-7 to Participant C. (13) Theoretical replication. (14) Make a decision or a summary of the result. In this way, the researcher elicited more in-depth responses and clarified the information when the participant did not understand the question (Olson \& Muise, 2009). Finally, the researcher transcribed the audio-recorded interview and then proceeded to qualitative content analysis using specific themes as the unit for the study.

\subsection{Data Analysis}

\section{Multi-Case Study}

Stage 1: Within Case Analysis.

- Each case analyzed as a case in itself (Creswell, 2007)

Steps:

1. Coding

2. Categorical Aggregation (group codes-theme)

3. Triangulation

4. Analytical Technique (relationship of variables to one another)

5. Direct interpretation

6. Rival Interpretation (theory)

Stage 2: Cross Case Analysis

- Creswell, 2007; Stake, 1995; Yin, 2009

- Similarities \& Differences

- General Explanation

\section{Stage 3: Analysis of Assertion}

- Meaning of cases - issues \& content, Explaining the strength and weaknesses of issues presented

\subsection{Ethical Consideration}

Research participants were made to fill up the consent form before answering the questionnaire and interview. The availability of the participants was noted and considered before conducting the meeting. The discussion venue was made sure to be wide enough to ensure the participant's comfort. Utmost confidentiality 
of the information shared, the researcher observed the audio-recording throughout the study. The names of the participants are just pseudo in the transcript.

\section{Findings and Discussion}

Based on the sharing of experiences with school administrators, processing of data collected in response to the research questions which were grouped into three themes and subthemes as follows:

\subsection{Stage 1. With-in Case Analysis}

\subsubsection{Forms of Bullying Handled by the School Administrators}

Theme 1. Verbal bullying-student to another student.

Most cases of bullying were more verbal. The majority were teased and called names; bad words threatened to be hurt, insulted and embarrassed, or laughed at for their appearance. Although there were also some cases of non-verbal, the bullies took their classmate's belongings.

Significant Statement 1." I oftentimes have verbal bullying case in the classroom like saying; you are not part of our group of friends."

Significant Statement 2. "One of my student's parent came to my office and complained that her child's name is written at the door of the comfort room."

Theme 2. Verbal bullying - student to pre-service teacher.

This type of bullying was experienced by the pre-service teacher of the Basic Education Department wherein a specific student uttered terrible words to the pre-service teacher when the student's cellular phone was confiscated for playing mobile legend during class hours.

Significant Statement 1. "A pre-service teacher relays her experience when a student uttered bad words at her when he confiscated the cellular phone for playing his phone legend during class hours."

4.1.2. Emerging Issues or Problems Encountered by the School Administrator in Handling Bullying Cases in the School

Theme 1. School administrators' problem with the bullies.

Bullies usually do not admit the truth at once. Their reluctance and fear of punishment and lack of confidence in adult responses to bullying hinder them from speaking up about what happened (Kowalski et al., 2012).

Significant Statement PA. "Most bullies make excuses by pointing one classmate to another classmate.

Significant Statement PB. "What the bully students relayed to his classmates is different from the information given to his parents.

Significant Statement PC. "The bully student cried once ask and could not answer the question what happened." 
Theme 2. School administrator problem on the bullied child or victim.

Most of the time, cases became complicated since bullied student do not inform the school authorities at once for fear of being scolded and bullied again. Instead, they likely report bullying to parents or friends rather than school staff (Limber et al., 2012).

Significant Statement PA. "The bullied child is afraid to tell the truth."

Significant Statement PB. "The bullied child usually does not attend class after the bullying incident."

Significant Statement PC. "Conflict sometimes arises if the classmate whom the bullied child tells what happened will not be able to relay the correct data of the incident."

Theme 3. School administrators' problem on the parents.

Some parents base the attitude of their child at home. Although they listened during the face-toface interview, they already have pre-judged the situation by siding on their child.

Significant Statement PA. "Sometimes parents of the bullied child call up or send text message blaming the teacher or the pre-service teacher for not attending to her child."

Significant Statement PB. "During our conference with parents of the bully child, parents were claiming that their child has no record of misbehavior in the previous grade levels."

Significant Statement PC. "Parents of the bully child defended that it is not the fault of their child. They don't believe the accusation given to their child".

Theme 4. Age challenging

There are cases where the school administrator is younger than the bully's parent or a subordinate.

Significant Statement PA. "There are times that both parents of the bully and bullied child are my friends. I have to be objective by listening to both sides and consider what is right".

Significant Statement PB. "I sometimes feel nervous with older guardian occupying higher work position both parties (bully and the bullied child). So, I just keep calm and do my role to interview them."

Significant Statement PC. "We have a case that I was about to lose my temper when the parent of the bullied child older than me came to my office and demanded me to see the student who bullied her child. Being a young principal, I sometimes face parents and guardian who are older than me. It's the violation of the child against the school policy, I am holding on, that gives me courage to face them."

Theme 5. Unclear school rules and policies on bullying

Significant Statement PA. "We refer to our student handbook for cases of bullying but the policies are general not specific." 
Significant Statement PB. "We find it hard resolving cases of Anti-Bullying using our University Handbook since the organizational structure or team assigned to settle the care is not clear."

Significant Statement PC. "We refer to our University Handbook to settle cases in bullying. But the guidelines in the handbook does not specify the punishment appropriate for the bully according to his age level."

Theme 6. Lack of expertise in handling cases of bullying

Significant Statement PA. "As a principal I feel the need of a training to be able to handle bullying cases appropriately."

Significant Statement PB. "One of my faculty was able to reveal to the parents of the bully sensitive cases of students being bullied."

Significant Statement PC. "Sometimes I feel I am not confident of my decision in resolving action. I need training how to handle issue on bullying."

\subsubsection{School Administrators Role in Handling Bullying}

Theme 1. Implement protocol of resolving the problem.

Significant Statement PA. "We tried our best to settle the problem first with the class adviser before bringing the issue to higher authorities."

Significant Statement PB. "I let the parent see the class adviser first before we settle the case of bullying in my office."

Significant Statement PC. "I talk to the child (bully and the bullied student) individually and scheduled separate meets with each part before we have a dialogue."

Theme 2. Documentation of the bullying incident and resolution process.

There are cases of bullying that have a psychological effect on the victim's part. Therefore, documentation is needed for the administrator to have a basis and arrive at an appropriate decision of the bullying incident.

Significant Statement PA. "I let the bully and bullied party write the incident of bullying, including the classmates who witnessed the incident."

Significant Statement PB. "We let our practice teachers who were avoiding the bullying incident write a narrative report."

Significant Statement PC. "I requested one faculty to take record of our dialogue with students and parents concern."

Theme 3. Improves classroom management techniques.

They found the following methods helpful and resolved the bullying situation: clear classroom policy: modeling, feedbacking, role-playing, movie on anti-bullying, and emotional messages on anti-bullying. "hugot lines."

Significant Statement PA. "After letting him see a short video on bullying, I asked the bully child, if you put yourself in the situation of the one you bullied what will you feel?" 
Significant Statement PB. "During our homeroom time once a week, we have feedbacking activity, wherein each one has a dialogue to express what he feels for himself and towards his classmates."

Significant Statement PC. "Part of their performance task requirement is to have a role play on bullying."

Theme 4. Enhancement of interactive activities in the academic and non-academic clubs

Spending time with students allows them to express their views and sentiments. Counseling bullies individually rather than in a group is essential to redirect their aggressiveness tendencies into power and leadership roles. (Mullin-Rindler, 2013) There are cases that misbehavior of a child is due to a bad experience at home or lack of attention from parents and siblings.

Significant Statement PA. "I observed in their dance club, they enjoy the dance steps which lessen the conflict."

Significant Statement PB. "We have math-club wherein students who are good in math mentor the slow learner in math. Members of the club became good friends."

Significant Statement PC. "Every week in our school we let our students play their favorite sports or go to their respective club. They try interacting one another."

Theme 5. Planning and immediate action.

It will help settle the problem by not prolonging the agony of both the bully and the bullied person.

Significant Statement PA. "We called up right away the attention of the students concern of bullying."

Significant Statement PB. "The class adviser inform the parents of the incident."

Significant Statement PC. "I conducted investigation with the students involved in bullying also the students who witnessed the incident."

Theme 6. Strengthen support through consultation and collaborative decision on bullying cases

Effective bullying prevention and intervention responses require support and commitment from school leaders, faculty, students, staff, adult mentor, and community partners. (Brodshaw et al., 2011).

Significant Statement PA. "I do not decide alone. I always consult my faculty and listen to their suggestion before I made a decision of the bullying case."

Significant Statement PB. "We discuss with my faculty the pros and cons of the punishment to be given to the bully students."

Significant Statement PC. "I consulted higher school authorities before inflicting punishment to the child involved in the bullying case."

\subsubsection{Suggested Bullying Intervention for School Administrators}

A clear policy on anti-bullying gives guidance to students, parents, and teachers on the appropriate decision concerning the issue. (Bradshaw et al., 2011).

Theme 1. Updated and clear school policy on anti-bullying. 
Significant Statement PA. "It will really help a lot if we have specific and updated student handbook on anti-bullying."

Significant Statement PB. "Resolving cases of bullying will not be hard for us administrators if we have updated clear policy on bullying."

Significant Statement PC. "The School Policy Students Anti-Bullying need to be revised and updated to fit with the current students and climate today."

Theme 2. Reward children for good behavior.

Rewarding the students will motivate them to demonstrate ethical behavior and serve as role models instead of punishing them.

Significant Statement PA. "Giving students awards is a good way to boost the confidence of the students."

Significant Statement PB. "Appreciating the students good deeds could help them and their performance in school."

Significant Statement PC. "Recognizing good deeds of the child will also help them perform good in school."

Theme 3. Bullying training or orientation.

Quality training, orientation management, and bullying prevention are a must for the school administrator, teacher, students, parents, and community stakeholders.

Significant Statement PA. "We could settle bullying concern confidently if we have the training."

Significant Statement PB. "Proper training to handle cases of bullying really help a lot to people involved in the resolution of bullying cases."

Significant Statement PC. "Training on how to handle cases of bullying help us resolve cases of bullying appropriately."

Theme 4. Effective and constant monitoring system.

A school-wide tracking system should document the frequency of bully or victims' problems like behavior referrals suspension/expulsion. Monitoring is to ensure the program's effectiveness on antibullying (Salmivalli, 2014).

Significant Statement PA. "I hope there is a personal team assigned to focus on the concerns of bullying to be able to give immediate action and monitoring the effectiveness of anti-bullying program."

Significant Statement PB. "The policy anti-bullying should be evaluated if it is responding to the needs of students."

Significant Statement PC. "Once the anti-bullying program is implemented it should be manifested."

Theme 5. Assigning trained peer mediator peer supporters.

The program enhanced bystanders' awareness, empathy, and self-efficacy to support victimized peers instead of reinforcing the bullies' behavior (Karna et al., 2011). Furthermore, assigning peers as educators involved in awareness campaigning on anti-bullying has been found effective in reducing bullying among adolescents (Palladino et al., 2015). Finland developed the KIVA anti-bullying program, which utilized peer mediators. 
Significant Statement PA. "I think assigning trained peer group to orient students on anti-bullying is good since it could help in the awareness campaign."

Significant Statement PB. "I suggest organizing students of their age to undergo training on handling bullying could help both the bully and bullied student."

Significant Statement PC. "I observed they feel comfortable sharing their experiences on bullying to students of their age."

Theme 6. Collaboration with parents and community

Significaant Statement PA. "As part of the school's extension program school authorities and community orientation on bullying prevention and help resolve similar cases in the community."

Significant Statement PB. "I believed problem on bullying could be minimized if parents will be actively involved in the solution."

Significant Statement PC. "Conduct of training program on bullying with the presence of school officials, represented for parents organization and community stakeholders of this will help connect misconnection and misdirections on bullying."

4.2. Stage 2. Common/Similarities

- Bullies do not admit/tell the truth at once.

- They both feel the need for training on the appropriate handling of bullying cases.

- No clear Bullying Policy.

-1st step dialogue

- Non-Academic clubs

- Class Advisers 1st Mediator

Differences

- Cause of intimidation (age and rank)

- Forms of Bullying (Verbal- Non-Verbal Bullying)

- Handbook on Bullying (Not clear guidelines/policy in other school while other no existing anti-bullying policy)

- Classroom Management Techniques.

\subsection{Stage 3. Analysis of Assertion}

- They do their roles and responsibilities, but their respective tasks are unclear.

- Sources of Problems (Bully, Bullied Child and Parents)

- School Heads and Lack of Expertise in Handling Bullying Cases

- Clear Policy on Anti-Bullying

- Sensitive to School Climate (nearsightedness and farsightedness attitude)

- Communication (Collaboration) 


\section{Impact/Outcomes of the Study}

Educators are in-charge of molding the youth mentally and with proper behavior. They are tasked to promote awareness of bullying and teach our students to be responsible for one's actions. The result of these research-based experiences and their unique role in addressing bullying of school heads will be used as a guide for bullying prevention and response in other schools. This will also provide an experience to preservice teachers on how to handle bullying cases inside and outside the classroom. Through deep examination and understanding of this study, it is hoped that educators and leaders will plan, update, and implement its Bullying Policy to create a safe and trusted learning environment and interactive classrooms that will assist in dealing with and preventing bullying.

\section{Conclusion}

Bullying has been a significant issue faced by school administrators and almost all schools worldwide. Its presence in school indicates the level of prosocial behavior and the lack of respect from one another and students to their teacher. This poses a big challenge on the part of the school administrators on their important role in addressing bullying and improving their resolving measures without compromising the school policy while considering the child's developmental stage. The challenge also includes school heads' leadership skills on coming up with a decision that is school-based and responsive to the current situation.

\section{Recommendation}

The study's result serves as a guide for students and teachers to give immediate response and action on the issue concerning bullying by recording the incident and reporting immediately to the appropriate school authorities. Parents and the community must also be a part of the solution by teaching their children proper behavior. This further gives school administrators a clear direction to develop a clear anti-bullying policy involving students, pre-service teachers' parents, and teachers themselves. Parents and the community must also be a part of the solution by their children on bullying and make their home "bully-free." Further studies can be conducted to address the cause, effects, and preventive measures of anti-bullying as a basis in the development of viable anti-bullying intervention programs and the offering of peace education.

\section{References}

Abu Sosha, G. (2012). Employment of Collaizi's Strategies in Descriptive Phenomenology: A Reflection of a Researcher. European Scientific Journal, (8)27. ISSN:1857-7881 (Print) e-ISSN 1857-7431.

Adams, C. (2006). Cyberbullying: What Teachers and Schools Can Do. and Related Disorders. 2009;7(3):221-230

Asimopoulos, C., Bibou, I., Hatzipemou, T., Soumaki, E., \& Tsiantis, J. (2013). International Journal of Mental Health Promotion: An investigation into students' and teachers' knowledge, attitudes and beliefs about bullying in Greek primary schools. International Journal of Health Promotion. DOI: 10.1080/14623730.2013.857823

Arnett, J.J. (2007). Emerging Adulthood: What is it and what is it good for Child Development Perspectives, 1, 68-73.

Bandura, A. (1977). Social learning theory. Englewood Cliffs, NJ: Prentice Hall.

Bradshaw, C.P., Sawyer, A.L. \& O' Brennan, L.M. (2007). Bullying and Peer Victimization at school: Perceptual differences between students and school staff. School Psychology Review, 36, 361-382.

Bradshaw, C.P., Waasdorp, T.E., O' Brennan, L.M. \& Gulemetova, M. (2011). Findings from the National Education Association's nationwide study of bullying: Teacher's and education support professional's perspectives. Retrieved from www.org/assets/docs/NationwideBullyingResearchFindings.pdf

Boulton, M.J., Murphy, D., Lloyd, J., Besling, S., Coote, J., Lewis, J., Perrin, R., \& Walsh, L. (2013). Helping counts: predicting children's intentions to disclose being bullied to teachers from prior social support experiences. British Educational Research Journal, (39)2, 209-221.

Casey-Cannon, S., Hayward, C., \& Gowen, K. (2001). Middle-school girls' reports of peer victimization: Concerns, consequences, and implications. Professional School Counseling, 5(2), 138-148. 
Creswell, J. W., \& Plano Clark, V. L. (2011). Designing and conducting mixed methods research (2nd ed.). Los Angeles, C.A.: Sage Publication.

Davies, L. (2003). Aggressive girls. Retrieved December 12, 2006 from http://www.kellybear.com/teacherarticles/teachertip39.html

Dellasega, C. (2005). Camp Ophelia: Arelationship camp for middle school girls [Electronic version]. Camping Magazine.

Edaño, D.C., Puzalan, E.M. \& Camus, A. (2016). Prevalence of Bullying and Intervention among the Pupils and Teachers in the Selected Public Elementary Schools in Region III, Philippines.

Flores, H. (2014). 1,700 Cases of Bullying Reported. http://www.philstar.com/metro/2014/07/28/1351137/1700-cases-bullying-reported.

Kallestad, S. H., and Olweus, D. (2003). Predicting Teachers' and Schools' Implementation of the Olweus Bullying Prevention Program: A Multilevel Study. Prevention and treatment, 6(I).

Karna, A., Voeten, M., Little, T., Poskiparta, E., Kaljonen, A., \& Salmivalli, C. (2011). A large scale evaluation of the KIVA antibullying program: Grades 4-6. Child Development, 82, 311-320.

Kowalski, R.M., Limber, S.P., \& Agatson, P.W. (2012). Cyberbullying: Bullying in the digital age. Malden, M.A.: Wiley-Blackwell

Merell, K.V. \& Carney, A.G. (2001). Bullying in Schools: Perspectives on Understanding and Preventing an International Problem.

Mishna, F., \& Alaggia, R. (2005). Weighing the risks: A child's decision to disclose peer victimization. Children \& Schools, 27(4), 217227.

Mullin-Rindler, N. (2003). Relational aggression: A different kind of bullying [Electronic version]. Principal, 82(5), 60-61.

Owens, L., Shute, R., \& Slee, P. (2000). Guess what I just heard: Indirect aggression among teenage girls in Australia. Aggressive behavior, 26, 67-83.

Paragus, E. T., and Paragas R. Y. (2016). Prevalence of Bullying in Rizal Technological University: A basis for proposed institutional guidelines and procedures. International Journal of Education and Research. Retrieved from http:///www.ijern.com/Journal/2016/May-2016/37.pdf

Reyes, A. (2016). Bullying Experienced among Indigenous People Students of Philippine Normal University North Luzon, Philippines: A Basis for Formulating School Policy. Alicia, Isabela, Philippines.

Salmivalli, C., Sentse, M., Kiuru, N., and Veenstra, R. (2014). A social network approach to the interplay between adolescents' bullying and likeability overtime. Journal of Youth and Adolescence, 43, 1409-1420. Doi:10.1007/s 1096-014-0129-4

Salmivalli, C. (2014). Participant Roles in Bullying: How Can Peer Bystanders Be Utilized in Interventions?, Theory Into Practice, 53:4, 286-292, DOI: 10.1080/00405841.2014.97222.

Smith P.K., Ananiadou K, Cowie H. (2013). Bullying and Victimization Among Children - NCBI

Palladino, B., Nocentini, A., \& Menesini, E. (2015). Evidence-based intervention against bullying and cyberbullying: Evaluation of the Notrap! program in two independent trials. Aggressive behavior, 194-206. Early online

Patton, M.Q. (2002). Qualitative research and evaluation methods, 3rd in Thousand Oaks: Sage Publications.

Pepler, D., Jiang, D., Craig, W., \& Connolly, J. (2008). Developmental trajectories of bullying and associated factors. Child Development, 79, 325-338.10.1111/j.1467-8624.2007.01128.x

Tenille, S. (2004). Bullying in School: A participatory action research study. Arizona State University, 292.

Tolentino, A.C. (2016). Bullying of Teachers in the Workplace: A Phenomenological Study

Ttofi, M. M., Farrington, D.P. (2011). Effectiveness of School-Based Programs to Reduce Bullying: A systematic and meta-analytic review. Journal of Experimental Criminology, 7, 27-56. doi:10.1007/s11292-010-9109-1

Waasdorp, T. E., Bradshaw, C. P. \& Duong, J. (2011). The link between parents' perceptions of the school and their responses to school bullying: Variation by child characteristics and the forms of victimization. Journal of Educational Psychology, 103(2), 324-335.

Wolke, D. and Woods, S. (2003). "Does the Content of Anti-Bullying Policies Inform us About the Prevalence of Direct and Relational Bullying Behavior in Primary Schools?". Educational Psychology, 23(4), 381-401.

Yoon, J. S., Barton, E., \& Taiariol, J. (2004). Relational aggression in middle school: Educational implications of developmental research. Journal of Early Adolescence, 24(3), 303-318.

Yoon, J. S., \& Barton, E. (2008). The role of teachers in school violence and bullying prevention. In School violence and primary prevention, 249-275. Springer New York. 6 Lucas-Moli 